\title{
Prevalence of Placenta Previa in Developing Countries and Its Association with Scarred and Unscarred Uterus
}

\author{
Sadia Asghar ${ }^{1, ~ *, ~ S a m r a ~ A s g h a r ~ C h e e m a ~}{ }^{2}$, Najaf Asghar Cheema ${ }^{2}$ \\ ${ }^{1}$ Department of Obstetrics and Gynecology, Naizi Medical College, Sargodha, Pakistan \\ ${ }^{2}$ Department of Obstetrics and Gynecology, Sir Ganga Ram Hospital, Lahore, Pakistan

\section{Email address:} \\ azanayan36@gmail.com (S. Asghar),smrcheema@gmail.com (S. A. Cheema), najafasghar@hotmail.com (N. A. Cheema) \\ ${ }^{*}$ Corresponding author
}

\section{To cite this article:}

Sadia Asghar, Samra Asghar Cheema, Najaf Asghar Cheema. Prevalence of Placenta Previa in Developing Countries and Its Association with Scarred and Unscarred Uterus. Journal of Gynecology and Obstetrics. Vol. 8, No. 4, 2020, pp. 98-101. doi: 10.11648/j.jgo.20200804.15

Received: June 9, 2020; Accepted: June 28, 2020; Published: July 17, 2020

\begin{abstract}
Placenta previa is an obstetric complication that occurs in the second and third trimester of pregnancy. It may cause severe feto-maternal morbidities and mortalities to mother and fetus. The risk of placenta previa increases with the history of cesarean section. In the presence of these two risk factors (placenta previa and previous cesarean section) incidence of placenta accrete spectrum is also increased. The value of making the diagnosis of placenta previa before delivery is important to involve for multidisciplinary planning in an attempt to minimize potential maternal or neonatal morbidity and mortality so the feto-maternal outcome can be optimized. The aim of the study is to determine the prevalence of placenta previa in developing countries like Pakistan and find out its association with scarred and unscarred uterus. It is a descriptive cross sectional study. 207 cases of placenta previa were found in six month of period, among them 138 patients were having previously scared uterus, and 69 were having previously unscarred uterus. Most patients 35.74\% were between 36-40 years age group, and presented with gestational age between 32-35 weeks were 53.62\%. Mostly found between G5-G7 i.e. 52.65\%. While frequency of placenta previa in scarred uterus was $66.66 \%$ and in unscarred uterus was $32.45 \%$. Association of placenta previa with previous four LSCS was found $33.33 \%$. Occurrence of major degree placenta previa was found $18.84 \%$ and minor was $81.15 \%$. Prevalence of placenta previa was found $5.78 \%$. Strong association was found between placenta previa and scared uterus which is highest with previous four. Our objective is to determine the frequency of placenta previa in scared and un-scared uterus. To minimize the rate of cesarean section we can reduce the feto-maternal morbidity and mortality, rising trend of cesarean section in turn increases the rate of placenta previa.
\end{abstract}

Keywords: Placenta Accreta Spectrum, Feto Maternal Outcome, Cross Sectional Study

\section{Introduction}

Placenta previa complicates $0.3 \%-0.5 \%$ of all pregnancies and is a major cause of third-trimester hemorrhage [1].

Almost $30 \%$ maternal deaths in the Asian population are due to major obstetrical haemorrhage in placenta previa, especially due to rise in the incidence of caesarean sections [2].

Significant maternal morbidity in the form of increased incidence of fetal malpresentation, cesarean delivery, increased blood loss and peripartum hysterectomy have been noted in cases of placenta previa and can lead to prolonged hospitalization in these women. Premature deliveries can occur which lead to higher admission to neonatal intensive care unit and stillbirths [1].

Traditionally, placenta previa has been classified according to the degree to which the placenta encroaches upon the cervix in labour, but in recent times, due to easy availability of transvaginal ultrasound, types and grades of placenta previa have been defined. Along with history, clinical examination and ultrasound (transabdominal and transvaginal), MRI (magnetic resonance imaging) has been used in patients with placenta previa, especially to diagnose adherent placenta. It has been speculated that uterine scarring due to trauma, infection or surgery lead to endo-myometrial junction abnormality causing abnormal vascularization which 
reduces the differential growth of the lower segment. This prevents placental migration as pregnancy advances [1].

Factors like advanced maternal age, previous placenta previa multiparity, multiple gestation, previous abortion and curettage and smoking during pregnancy have also been associated with placenta previa [2, 3]. It is obstetric complication [4].

The estimated global prevalence of placenta previa is 5.2 per 1000 pregnant women, although there is significant variation where by the prevalence was highest among Asian population and lower in sub sharan Afriqa studies [5]. Diagnosis of placenta previa is made during the second half of pregnancy by vaginal and transabdominal sono graphy [6, 7]. Such abnormal placentation has been observed and show relationship with previous cesarean section [8, 9]. Uterine scar is major risk factor for placenta previa and its complication like accreta increta and percreta etc [10].

Cesarean sections constituted $25 \%$ of National Health Service (NHS) deliveries during 2010, and the rates have been rising for both primary and emergency cesarean section [11].

The prime factors responsible for neonatal morbidity and mortality in case of placenta previa is prematurity [12].

The aim of this study was to determine the prevalence of placenta previa and frequency of placenta previa in scarred and unscarred uterus.

\section{Subject and Method}

A cross sectional survey was conducted for the period of 6 months from January 2018 to June 2018 in obstetrics and gynecology department of, Ganga Ram Hospital, a teaching hospital of Pakistan. A non - probability purposive sampling techniques was adopted for enrolling the patients of placenta previa. Sample size of 207 pregnant females with placenta previa with confidence level of $95 \%$ and $10 \%$ margin of error were calculated by WHO manual.

Patients, fulfilling the inclusion criteria i.e. age of the patient was between 20-40 years, gestational age should be between $\geq 28$ - 40 weeks, gravidity was between G2 $\geq$ G7, type of placenta previa both minor and major, and previous cesarean section from previous 1 to previous 4 , also the patients with unscarred uterus were included.

Pregnant females with first gravida, second trimester bleeding, scar on uterus other than cesarean section like myomectomy, and patient with bleeding disorders like decreased platelet counts or deranged coagulation profiles were excluded. Data was collected from all those patients who fulfill the inclusion and exclusion criteria presented in outpatient and emergency department of Ganga Ram Hospital. Detailed history was taken, regarding age, gravidity, duration of gestation, type of placenta previa (minor or major) and number of previous cesarean sections in scarred uterus were noted.

All the information was collected through especially designed performa. Informed consent was taken from the patient and data was kept anonymous for privacy. All the collected data was entered into SPSS version 23. Data was presented as frequency and percentages.

\section{Result}

Total deliveries in the above mentioned period were 3581 .

Age distribution of the patients, was done where in 30 (14.49\%) patients between 20-25 years of age group, 64 (30.91\%) between $26-30$ years, 39 (18.84\%) between 31 35years, and only 74 (35.74\%) were between $36-40$ years (Table 1).

Gestational age of the patients revealed $44(21.25 \%)$ between 28-31 weeks, 111 (53.62\%) between 32-35 weeks, and $52(25.12 \%)$ between $36-40$ weeks (Table 2).

Gravidity $67(32.36 \%)$ were between G2 - G4, 109 (52.65\%) were between G5 - G7 and 31 (14.91\%) were more than G7 (Table 3).

In this study $168(81.15 \%)$ patient were found with placenta previa major type and $39(18.84 \%)$ were found with placenta previa minor (Table 4).

Segregation of patient for placenta previa according to previous cesarean section was done which showed that out of 138 cases of placenta previa, 25 (12.07\%) had history of one LSCS, $61(29.46 \%)$ patients had previous two LSCS, while $52(25.12 \%)$ had previous three LSCS and $69(33.33 \%)$ had previous four LSCS. (Table 5)

In this study, $138(66.66 \%)$ patients of placenta previa had scarred uterus while $69(32.45 \%)$ patients of placenta previa had previous vaginal deliveries (unscarred uterus) (Table 6, Figure 1).

The prevalence of placenta previa in developing countries was found $5.78 \%$ (Table 7).

Table 1. Age of pregnant females with placenta previa.

\begin{tabular}{llll}
\hline $\begin{array}{l}\text { Serial } \\
\text { number }\end{array}$ & Age of patient & $\begin{array}{l}\text { Number of } \\
\text { patient (207) }\end{array}$ & Percentage \% \\
\hline 1 & $20-25$ & 30 & 14.49 \\
2 & $26-30$ & 64 & 30.91 \\
3 & $31-35$ & 39 & 18.84 \\
4 & $36-40$ & 74 & 35.74 \\
\hline
\end{tabular}

Table 2. Gestational age of pregnant females with placenta previa.

\begin{tabular}{llll}
\hline $\begin{array}{l}\text { Serial } \\
\text { number }\end{array}$ & $\begin{array}{l}\text { Gestational age } \\
\text { (weeks) }\end{array}$ & $\begin{array}{l}\text { Number of } \\
\text { patients }(\mathbf{2 0 7})\end{array}$ & $\begin{array}{l}\text { Percentage } \\
(\%)\end{array}$ \\
\hline 1 & $28-31$ & 44 & 21.25 \\
2 & $32-35$ & 111 & 53.62 \\
3 & $36-40$ & 52 & 25.12 \\
\hline
\end{tabular}

Table 3. Gravidity of pregnant females with placenta previa.

\begin{tabular}{llll}
\hline Serial number & $\begin{array}{l}\text { Gravidity of } \\
\text { patient }\end{array}$ & $\begin{array}{l}\text { Number of } \\
\text { patient (207) }\end{array}$ & Percentage (\%) \\
\hline 1 & G $2-\mathrm{G} 4$ & 67 & 32.36 \\
2 & $\mathrm{G} 5-\mathrm{G} 7$ & 109 & 52.65 \\
3 & $>\mathrm{G} 7$ & 31 & 14.9 \\
\hline
\end{tabular}

Table 4. Type of placenta previa.

\begin{tabular}{llll}
\hline $\begin{array}{l}\text { SERIAL } \\
\text { NUMBER }\end{array}$ & Type of previa & $\begin{array}{l}\text { Number of } \\
\text { patients }(\mathbf{2 0 7})\end{array}$ & $\begin{array}{l}\text { Percentage } \\
(\mathbf{\%})\end{array}$ \\
\hline 1 & Minor & 39 & 81.15 \\
2 & Major & 168 & 18.84 \\
\hline
\end{tabular}


Table 5. Number of previous cesarean section in pregnant females with placenta previa.

\begin{tabular}{llll}
\hline $\begin{array}{l}\text { Serial } \\
\text { number }\end{array}$ & $\begin{array}{l}\text { Number of previous } \\
\text { cesarean section }\end{array}$ & $\begin{array}{l}\text { Number of } \\
\text { patient }(\mathbf{2 0 7})\end{array}$ & $\begin{array}{l}\text { Percentage } \\
(\%)\end{array}$ \\
\hline 1 & 1 & 25 & 12.07 \\
2 & 2 & 61 & 29.46 \\
3 & 3 & 52 & 25.12 \\
4 & 4 & 69 & 33.33 \\
\hline
\end{tabular}

Table 6. Frequency of placenta previa in scarred and un scarred uterus.

\begin{tabular}{llll}
\hline $\begin{array}{l}\text { Serial } \\
\text { number }\end{array}$ & Groups & $\begin{array}{l}\text { Number of } \\
\text { patients (207) }\end{array}$ & Percentage (\%) \\
\hline 1 & Scarred uterus & 138 & 66.66 \\
2 & Un scarred uterus & 69 & 32.45 \\
\hline
\end{tabular}

\section{Frequency of Placenta Previa in scarred and unscarred uterus}

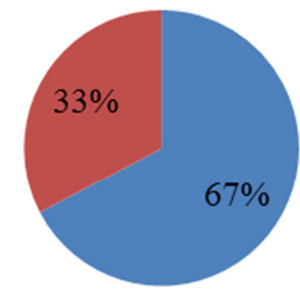

n Scarred

un Scarred

Figure 1. Frequency of placenta previa in scarred and un scarred uterus.

Table 7. Prevalence of Placenta Previa.

\begin{tabular}{lll}
\hline Total Patients & Total Placenta Previa & Prevalence \\
\hline 3581 & 207 & $5.78 \%$ \\
\hline
\end{tabular}

\section{Prevalence of Placenta Previa}

Total Patient $\quad$ Prevalence of placenta previa

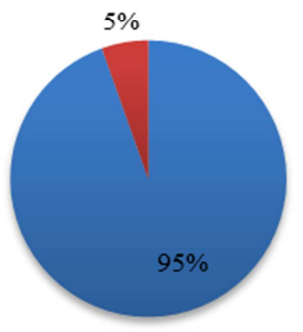

Figure 2. Prevalence of Placenta Previa.

\section{Discussion}

Placenta previa can have serious adverse consequences for both mother and baby, including an increased risk of maternal and neonatal mortality [13-15], fetal growth restriction and preterm delivery [16], antenatal and intrapartum hemorrhage [17-19], and women may require a blood transfusion [11] or even an emergency hysterectomy. It is a relatively uncommon condition, with an overall incidence in
England of 6.3 per 1000 births [8]. The risk of placenta previa in a pregnancy after a cesarean section has been reported to be between 1.5 and 6 times higher than after a vaginal delivery. A meta-analysis of studies published before 2000 of previous cesarean section as a risk factor for placenta previa found an overall odds ratio of 2.7 [8].

The incidence is $2 \%$ after one previous caesarean section, $4.1 \%$ after two and $22 \%$ after three [20]. Similarly dilation and curettage, evacuation of uterus and myomectomy are associated with placenta praevia. Placenta praevia is more common in older and multi-parous women [10, 12, 21]. The reason is not clear but it may be associated with the ageing of vasculature of the uterus. This causes placental hypertrophy and enlargement which increases the likelihood of the placenta encroaching on lower segment [10].

In this study, Segregation of patients for placenta previa according to previous cesarean section was done which showed that out of 138 cases of placenta previa, $25(12.07 \%)$ had history of one LSCS, $61(29.46 \%)$ patients had previous two LSCS, while $52(25.12 \%)$ had previous three LSCS and $69(33.33 \%)$ had previous four LSCS. (Table 5)

In this study, $138(66.66 \%)$ patients of placenta previa had scarred uterus while $69(32.45 \%)$ patients of placenta previa had previous vaginal deliveries (unscarred uterus) (Table 6, Figure 1). Overall prevalence of placenta previa in Pakistan is about 5\% (Figure 2). Estimated global prevalence of placenta previa is 5.2 per 1000 pregnant women although there is significance variation where by the prevalence is highest among the Asian population as compared to sub sahran Africa [5]. So the frequency of placenta previa is more in Pakistan (Third world country) as compared to developed countries due to rising trend of cesarean section.

\section{Conclusion}

It is concluded from the study that there is strong association between scarred uterus and incidence of placenta previa, and also as the number of cesarean section increases the frequency of placenta previa is also increased. This study concludes that efforts should be made to reduce the rates of cesarean section because there is greater likelihood of placenta previa in scarred uterus in subsequent pregnancies. In conclusion, primary prevention in the form of reduction in the rate of primi-caesarean section must be done in order to prevent likelihood of placenta previa in scarred uterus. The emphasis should be on institutional delivery in a tertiary care centre with multidisciplinary care i.e. involvement of senior obstetrician, neonatologist, Sonologist and Hematologist. Early diagnosis by Ultrasound and planned delivery should be the goal The morbidity associated with placenta previa can be reduced by detecting the condition in the antenatal period by ultrasound, before it becomes symptomatic. This may need educating our patients and making them aware of the importance of antenatal care and its availability. 


\section{Disclosure}

The authors declare that they have no competing interests.

\section{Acknowledgements}

We are thankful to all women participating in this study.

\section{References}

[1] Hung TH, Hsieh CC, Hsu JJ, Chiu TH, Lo LM. Risk factors for placenta previa in an Asian population. International Journal of Gynecology and Obstetrics. 2007; 97 (1): 26-30.

[2] Ahmed S. Major Placenta Previa: Rate, Maternal and Neonatal outcomes experience at a tertiary maternity hospital, Sohag, Egypt: a prospective study. JCDR. 2015.

[3] Mathuriya G, Lokhande P. Comparative study of obstetric outcome between scarred and unscarred uterus in placenta previa cases. Indian Journal of Clinical Practice. 2013; 24 (6).

[4] L. Latif, U. J. Iqbal, and M. U. Aftab, “Associated risk Factors of placenta Previa a matched case control study,"Pakistan Journal of Medical and Health Science, Vol. 9, nou, pp. 13441346, 2015.

[5] J. A. Cresswel 1, C. Ronnsmans, C. Calvert, and V. Fillipi”, Prevelance of placenta previa by world region: a systematic review and mata analysis. Tropical medicine and international Health, vol. 18, No. 6, PP. 712 724, 2013 view at publisher view at Google scholar. view at scopus.

[6] ACOG. Placenta accrete, Committee Opinion 2012; 529: reaffirmed 2015.

[7] Wu. S, Koch erinsky M, Hibbard JU. Abonormal Placentation: twenty -year nalysis. Am J Obstet Gynecol 2005; 192: 1445861.

[8] Faiz AS. Ananth CV. Etiology and risk for placenta previa and overview and meta analysis of observational studies. J Matern Fetal Neonatal Med 2003; 13: 175-90.

[9] Jaunioun E, Collins S, Burton GJ. Placenta accrete spectrum pathophysiology \& evidence based anatomy for prenatal ultrasound imaging. Am J Obstet Gynecol 2017; 17: 3073130737.
[10] Getahun D, Oyelss Y, Salihu HM, Anantha CV. Previous cesarean section delivery and risk of placenta previa and placenta abruption. Obstet Gynecol. 2006. Apr; 107 (4): 771778 .

[11] HESOnline. 2011. http://www.hesonline.nhs.uk/.

[12] Odibo AO, Chahilla AG, Stamilio DM, Stevens EJ, Peipert JF, Macones GA. Predicting placental abruption and placenta previa in women ith pevious cesarean delivery Am J Perinatal. 2007 May; 24 (5): 299-305.

[13] Shreyasi S, Chanchal S, Sohani V, et al. Prenatal diagnosis \&management of morbidly adherent placenta. J Clin Diagn Res. 2017; 11: 1-2.

[14] Chaudhari HK, Shah PK, D'Souza N. Morbidly adherent placenta: its management \& maternal \& perinatal outcome. J Obstet Gynecol India 2017; 67: 42-47.

[15] Tikkanen M, Stefanovic V, Paavonen J. Placenta previa percreta left in situ-management by delayed hysterectomy: a case report. Journal of Medical Case Reports 2011: 5: 418-421.

[16] Brace V, Kernaghan D, Penney G. Learning from adverse clinical outcomes: major obstetric haemorrhage in Scotland, 2003-05. BJOG. 2007; 114 (11): 1388-1396. doi: 10.1111/j.1471-0528.2007.01533.x.

[17] Crane JMG, Van den Hof MC, Dodds L, Armson BA, Liston R. Maternal complications with placenta previa. Am J Perinatol. 2000; 17 (2): 101-105. doi: 10.1055/s-2000-9269.

[18] Bhide A, Prefumo F, Moore J, Hollis B, Thilaganathan B. Placental edge to internal os distance in the late third trimester and mode of delivery in placenta praevia. BJOG. 2003; 110 (9): 860-864. doi: 10.1111/j.1471-0528.2003.02491.x.

[19] Lydon-Rochelle M, Holt VL, Easterling TR, Martin DP. Firstbirth cesarean and placental abruption or previa at second birth. Obstet Gynecol. 2001; 97 (5): 765-769. doi: 10.1016/S0029-7844(01)01121-8.

[20] Lala ABH, Rutherford JM. Massive or recurrent ante partum haemorrhage. Current Obstetrics and Gynaecology. 2002; 12: 226-230.

[21] Eniola AO, Bako AU, Selo-Ojeme DO. Risk factors for placenta praevia in southern Nigeria. East Afr Med J. 2002; 79: 535-538. 